\title{
Research at a Distance: Area Studies in the Post- Pandemic Era
}

\author{
Jin Sato, Editor-in-Chief \\ University of Tokyo
}

\section{Research without Fieldwork}

"Professor, how can I do research without fieldwork?" A graduate student of mine posed this question to me in March 2020 when COVID-19 began impacting air travel around the world. In anticipation of further restrictions through the summer of 2020, and perhaps even longer, I held an online session with all my graduate advisees to discuss the meaning of fieldwork in a broader context of area studies research.

My message, in short, was that in fieldwork the discovery of something worth writing about is almost like a bonus. More important is the "deskwork" you do prior to the field research - the formulation of your research question and hypothesis, and the basic structure of the argument. That is what prepares you to capture that observation on the field as something valuable. Of course, field research will allow you to cross-check and perhaps modify your question and hypothesis. But that is more of an elaboration; the bulk of your research, thus, can be formed without fieldwork. I did not mean to deny the value of fieldwork; rather, I meant to play up the potential of deskwork under this challenging condition.

I advised my students to reformulate their questions in a way such that there is no desperate need to go to the field. Having said that, I realized that my opinion continues to rely on the availability of fieldwork, since if the "empirical check" cannot be done on-site, we have no means to know if one hypothesis is better than another. This would certainly be a critical question for $\mathrm{PhD}$ students in the time of this pandemic. After all, is area studies possible without fieldwork? The answer to this depends on what we aim to achieve by area studies and its place in the broader community of humanities and social sciences.

Resource constraints due to the pandemic forced each organization in our society to identify "essential workers" relevant to its mandate. Likewise, research institutions may face a similar challenge of having to categorize what constitutes "essential scholar(ship)." The question boils down to the value of humanities and social sciences relative to other disciplines in universities. Under the pressure not only in research but also in education at home on budget, space, and personnel, a stronger case must be made in order to claim that area studies is "essential." The bigger question is, essential in what? Before claiming how essential area studies is in the context of institutional politics at universities, perhaps this is a good opportunity to reflect on the essence of our work within our discipline.

Like it or not, COVID-19 gave us an opportunity to think about what is essential in our profession. Undeniably, while most of us find that online means are useful especially in teaching, the question remains as to what needs to be done in person. Those who have extensive fieldwork experience in developing countries, including myself, would have to admit that the majority of the time spent in the field is "non-essential" or irrelevant to actual data collection that directly responds to our research questions: listening to apparently irrelevant anecdotes, learning that documents are missing after getting to the libraries, being stuck in a car in a traffic jam, waiting for the interviewee who never shows up, etc.

(c) Cambridge University Press 2020 
Having said that, we also know from experience that such non-essential times are an indispensable part of fieldwork experience and often produce valuable insights into the culture of the place in question. Of course, not all area studies require such on-site fieldwork, and efforts to compile useful resources on "Doing Fieldwork in a Pandemic" in the post-COVID-19 era are on the way (Lupton 2020). These include various online techniques and methods for using local friends and connections to access field information remotely. The new normal forces us to be innovative in conducting "research at distance." It challenges our ingenuity, the intellectual efforts that would not have come about without the pandemic.

Because of the increasing layers of risks and physical hurdles, on-site studies on foreign countries will be ever more challenging. The number of students who dare to go and visit a place with poor health facilities and hygiene would likely decrease at least for the next couple of years. Yet, remember that area studies specialists in developing countries are increasingly trained to study their own region and culture from a broader perspective. The recent rise of "Global Japan Studies" propagated mostly by scholars based in Japan is one such example. From the perspective of scholars based in a foreign country, the pandemic may be giving them the opportunity to read more of what has been written by such "indigenous" authors and explore the potential of research conducted at a distance. Against this background, I now discuss the meaning of "area" and its significance as an academic subject.

\section{Toward a Broader Understanding of "Area"}

A majority of the post-war area studies scholars in the past have traditionally confined themselves to a study of a particular foreign country, including training in language and other cultural skills. This confinement is understandable, since after so much investment in the study of a particular country, it becomes too costly to switch to another country. However, I argue that in the post-pandemic age, area studies specialists must break away from their comfort zones to address cross-regional issues and identify the nature of inter-dependencies among the nations more than before.

Global crises, whether natural or man-made, have revealed the extent of our interdependence that is taken for granted. The situation in one area is increasingly more conditioned by situations in other areas. We need to rethink the boundaries and definition of "area." Of course, this has been an ongoing discussion since the Cold War ended and globalization penetrated so deeply into our lives. Yet we have seen in the past decade, perhaps intensified by COVID-19, the rise of inward-looking nationalism with racial sentiment increasingly dominating international affairs. As governments try to control and limit certain aspects of the global flow of people and goods, there is more need to examine the impact of such policies on various layers of domestic societies. This approach must go beyond the study of globalization, beyond treating nations as homogeneous given, in order to bring more attention to bear upon the inequalities within - and between - nations.

In searching for past wisdom, let us look at the dawn of modern Japan, when, during its long period of isolation, area studies began and fieldwork was still a rare luxury. It was only in 1860, with its first official embassy to the West after its opening, that the Japanese could go out to the "field" to observe and document various aspects of Western civilization. Until then, "research at a distance" was the norm, especially since international travel was extremely restricted. Yet the following passage from the autobiography of Fukuzawa Yukichi (1835-1901), who was one of the younger members of the embassy, suggests that his "deskwork" i.e., Dutch Learning, had equipped him with sufficient knowledge of Western technologies even before he had the chance to see them for himself in the United States. Fukuzawa reflects on his visit:

I am sure that our hosts thought they were showing us something entirely new, naturally looking for surprises at each new device of modern engineering. But on the contrary, there was really nothing new, at least to me. I knew principle of the telegraphy even if I had not seen the actual machine before ... I had been studying nothing else but such scientific principles ever since I had entered Ogata's school (Duus 1997, p. 149). 
What surprised Fukuzawa was, rather, the amount of apparently trivial social, political, and economic issues that had been left out of documentation in books, like garbage waste and the cost of daily commodities such as oysters. We notice that his observation is always examined in contrast to his deep knowledge of the parallel situation in Japan. Perhaps this two-way learning system is one of the most important lessons we can learn from the early years of fieldwork.

During that time, elite scholars experienced a dramatic transformation, from being experts in Chinese classics to needing to become experts in Western civilization. Fukuzawa described, in his definitive work, An Outline of a Theory of Civilization (『文明論之概略』) , the peculiar dual life of the scholars in Japan at that time:

Consider how all of today's scholars of Western Learning were, but a few years back, students of Chinese Classics, or of Shinto or Buddhism. We were all either from feudal samurai families or were feudal subjects. We have lived two lives as it were; we unite in ourselves two completely different patterns of experience. What kind of insights shall we not be able to offer when we compare and contrast what we experienced in our earlier days with what we experience of Western civilization? What we have to say is sure to be trustworthy... My only wish is that later scholars will undertake wider studies, reading more Western books than I have been able to, and studying the Japanese situation in greater detail, that they may be able increasingly to broaden their perspectives and to refine the problem such that they can truly write a complete theory of civilization (revised translation by David A. Dilworth and G. Cameron Hurst, III. An Outline of a Theory of Civilization, pp. 3-4. Columbia University Press, 2008).

I am recalling this nineteenth-century passage in the present-day post-COVID-19 era not just to remind us how area studies started as "research at a distance" but more because Fukuzawa's insight into the value of studying others has contemporary relevance. The study of Western civilization was not simply one-way, where the Japanese only learned about the West. As stated in the above quote, Fukuzawa emphasized the importance of comparison and cross-confirmation to establish a firm foothold on one's world view. Difficulty of access to data should not blind us to this fundamental value of area studies, which entails acute awareness of one's own culture in a global perspective.

Since the end of World War II, the movement of people has become increasingly central to the craft of scholarship since the 1950s. As scholars, we are expected to attend workshops and conferences, visit libraries, and go out into the field. Doing research involves moving, and doing area studies without moving is almost unthinkable; but we may have forgotten the wisdom of Fukuzawa, who suggested that we investigate ourselves instead of focusing solely on others. Naturally, the flow of people encourages the interactions of ideas. Although without fieldwork scholars may miss the accidental benefits unique to direct person-to-person contact, we may still secure the flows of ideas online and on paper. If we ensure our internal freedom of imagination and ideas, our scholarship shall survive.

\section{Why Publish with Our Journal Now?}

So how can this journal promote post-pandemic imagination? Let me introduce some changes to our general polity that we plan to implement in response to the "new normal."

I highlight three points to make the case. First, this journal offers a platform for works on both humanities and social sciences. While we continue to welcome rigorous works in humanities and history, this journal will aim to provide a wider platform for area studies, including the social sciences. Various parts of Asia are observing the expansion of state power in the face of uncertainty, as highlighted by the tension between privacy and state surveillance. A penetrating study of "governance" is needed more than ever.

Second, we welcome pre-researched but insightful ideas in the form of short "perspectives" that may open new fields of investigation and lead to substantial work in the future. To facilitate discussion and movement of ideas, particularly among those who are at an earlier stage of their career working on 
dissertations, we will occasionally set up a "dissertation flash," where $\mathrm{PhD}$ students can showcase their working hypotheses and invite critiques. We also wish to include "debates" in this short-paper category, based on reviews of the existing literature or responses to proposed theses that might interest Asian studies scholars broadly. These idea-based short pieces are somewhat against the tradition of area studies where empirical data are given higher value. However, what becomes data depends on what questions and methods we apply. Short pieces will also be subject to peer review, but we plan to design the review process so that the response time will be much shorter.

Third, we emphasize Asian voices that can communicate with and penetrate scholars of the West. We encourage authors based in Asia who can speak to and challenge some of the dominant discourses originating from Western academia. We are all aware that there are many Asian scholars actively publishing in the US and Europe who are well connected to the more privileged groups in academia that give them a better chance to publish in English. English-writing scholars based in Asia are more disconnected and often work in isolation. They may be facing demands to publish in their local languages as well. Emphasis on the "Asian voice" is not to say that genuine voices can only be heard from scholars residing in Asia. This message simply seeks to encourage critical thinking on what unique contributions regional experts can offer to supplement, or potentially transform, perspectives dominant in the Western research community.

The global crises ignited by COVID-19 may give area studies a particularly hard time. Area studies has been given a death sentence by traditional disciplines such as political science for quite some time already (Sil 2020); yet it is not the survival of area studies that matters, but rather the quality of individual works. Our journal will strive to maintain such quality by offering an open platform for advanced discussions of Asia - across disciplines - with confidence that area studies is indeed "essential" scholarship.

\section{References}

Dilworth David and G. Cameron Hurst, III. (2008). An Outline of a Theory of Civilization, pp. 3-4. New York: Columbia University Press.

Duus Peter (1997). The Japanese Discovery of America: A Brief History with Documents. Boston: Bedford Books.

Lupton D. (2020). Doing Fieldwork in a Pandemic. Crowdsourced document initiated by Deborah Lupton on 17 March 2020. https://nwssdtpacuk.files.wordpress.com/2020/04/doing-fieldwork-in-a-pandemic2-google-docs.pdf

Sil R. (2020). The Survival and Adaptation of Area Studies. Sage Handbook of Political Science. London: Sage.

Cite this article: Sato J, Editor-in-Chief (2020). Research at a Distance: Area Studies in the Post-Pandemic Era. International Journal of Asian Studies 17, 105-108. https://doi.org/10.1017/S1479591420000376 